\title{
Examination of the interaction of different lighting conditions and chronic mild stress in animal model
}

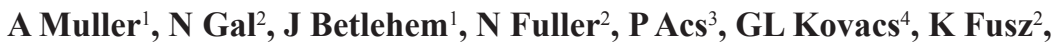 \\ R Jozsa ${ }^{5}$, A Olah ${ }^{2}$ \\ ${ }^{1}$ Institute of Emergency Care and Pedagogy of Health, Faculty of Health Sciences, \\ University of Pécs, Pécs, Hungary \\ ${ }^{2}$ Institute of Nursing Sciences, Basic Health Sciences and Health Visiting, Faculty of Health Sciences, \\ University of Pécs, Pécs, Hungary \\ ${ }^{3}$ Institute of Physiotherapy and Sport Sciences, Faculty of Health Sciences, University of Pécs, Pécs, Hungary \\ ${ }^{4}$ Institute of Diagnostics, Faculty of Health Sciences, University of Pécs, Pécs, Hungary \\ ${ }^{5}$ Department of Anatomy, Medical School, University of Pécs, Pécs, Hungary
}

Received: February 10, 2014

Accepted after revision: June 17, 2015

\begin{abstract}
We examined the effects of different shift work schedules and chronic mild stress (CMS) on mood using animal model. The most common international shift work schedules in nursing were applied by three groups of Wistar-rats and a control group with normal light-dark cycle. One subgroup from each group was subjected to CMS. Levels of anxiety and emotional life were evaluated in light-dark box. Differences between the groups according to independent and dependent variables were examined with one- and two-way analysis of variance, with a significance level defined at $p<0.05$. Interaction of lighting regimen and CMS was proved to be significant according to time spent in the light compartment and the average number of changes between the light and dark compartments. Results of our examination confirm that the changes of lighting conditions evocate anxiety more prominently than CMS. No significant differences were found between the results of the low rotating group and the control group, supposing that this schedule is the least harmful to health. Our results on the association between the use of lighting regimens and the level of CMS provide evidence that the fast rotating shift work schedule puts the heaviest load on the organism of animals.
\end{abstract}

Keywords: modelling of shift work, chronic mild stress, light-dark box test, anxiety, animal models, shift work

A growing number of international scientific researches examine the influence of working conditions on employees in health care. Frequent changes in schedule, disrupting the circadian rhythms in shift workers, can lead to chronic fatigue and psychosomatic diseases $(14,18,35)$ such as gastrointestinal (22) and cardiovascular diseases $(7,23)$, and may also increase the risk of tumors (36) and premature birth (25).

Several researches argue that the risk of breast cancer is higher by those working on night shifts $(10,17)$. Depression may also develop as a result of chronic disturbances in the circadian rhythms (e.g. sleeping-being awake) (13). According to the study of Arimura et al. shift work and poor mental health were significant factors leading to medical errors among Japanese hospital nurses (2). Another study examined the number of days off required after night shift to recover the quality of sleep. It was determined that sleeping time is significantly

Corresponding author: Andras Olah RN, MNS, PhD, associate professor Institute of Nursing Sciences, Basic Health Sciences and Health Visiting Faculty of Health Sciences, University of Pécs

Vörösmarty u. 4, H-7621 Pécs, Hungary

Phone: +36-72-513-670; Fax: +36-72-513-671; E-mail: andras.olah@etk.pte.hu 
higher on rest days than on active days, thus the minimum of 4 consecutive days off after 5 days of night shifts was recommended (27). Significant difference was found for the dropping level of alertness by the $7^{\text {th }}$ and $10^{\text {th }}$ shifts in case of a one night shift - one day off working period, putting secure medical attendance to high risk (4).

The examination of the effects of daily or shorter and longer rhythms and the effects of different factors on them is becoming more prominent. Our review of the relevant literature revealed that there is a lack of manuscripts covering research using animal models to examine different types of night shifts beside the rectification of changes in hormonal system and mood. Therefore, our research group developed an animal model that allows the examination of the biological rhythms of hormones, even for several weeks.

In this survey we intended to examine the effects of different types of night shift work schedules also applied in the course of nursing (different lighting regimens) and the effect of chronic mild stress (CMS) on animals' mood, with the application of an animal model. We also intended to find which night shift schedule would prove to be least harmful among the different types of shift work schedules. The reason for using animal models was the intention to study primarily the undesirable health effects of lighting conditions. CMS protocol, known from literature, is an accepted model for examination of stress and depression. Grippo et al. found that the motor activity of animals exposed to chronic mild stress decreased and they consumed significantly less sugar - which is a sign of anhedonia - compared to control animals (15). Grønli et al. conducted a survey on rats examining whether CMS protocol results in decreased sugar intake and whether similar changes in sleeping habits can be detected compared to the case of patients suffering from depression. As a result, sugar intake of animals which were exposed to CMS decreased, they spent more time in REM sleep, and showed more fragmented sleep (16). However, research findings contradict sometimes as stress is not necessarily accompanied by decreased sucrose intake, as it has been confirmed by our earlier findings as well $(9,19,28,29,30,31,32)$.

It is possible to examine anxiety-like behavior in animal experimental models with the joint employment of different tests, such as tests for novel object recognition, sucrose consumption and fear conditioning, as well as an open-field and light-dark box test (12). These examinations can be used effectively in experiments with antidepressants $(3,21)$. Through the application of a light-dark box test, also used in the current study, the anxiety of animals can be proved by the fact that animals exposed to CMS spend significantly less time in the light compartment of the light-dark box, and the number of changes between the light and dark compartments is less than in case of those that are not exposed to CMS $(1,3,6,20)$.

\section{Material and Methods}

\section{Animals}

We have examined four-month-old Wistar rats $(n=61)$, weighing $275 \mathrm{~g}$ on average. The rats were provided by the Department of Anatomy at the Medical School of University of Pécs, Pécs, Hungary. It is a widely known fact that rats are active in the dark (D) and they rest in light (L). They were exposed to a reverse lighting condition in night shift periods. The rats were divided into four groups. In case of three groups a middle rotating night shift schedule (4DL/3LD: 4 night shift working days followed by 3 days off -4 days on DL, alternating with 3 days on LD), a low rotating night shift schedule (8DL/6LD: 8 night shift working days followed by 6 days off -8 days on DL alternating with 6 days on LD) and a fast rotating night 
shift schedule (2DL/2LD: 2 night shift workdays followed by 2 days off -2 days on DL, Dark $_{06-18}$ Light $_{18-06}$, then 2 days on LD, Light ${ }_{06-18}$ Dark $_{18-06}$ - explanation of indices can be found in Table I) were modeled, parallel to nursing work schedules. Results of the four sample groups were compared to a group of rats kept in a normal (LD/DL) cycle (18) (Table I).

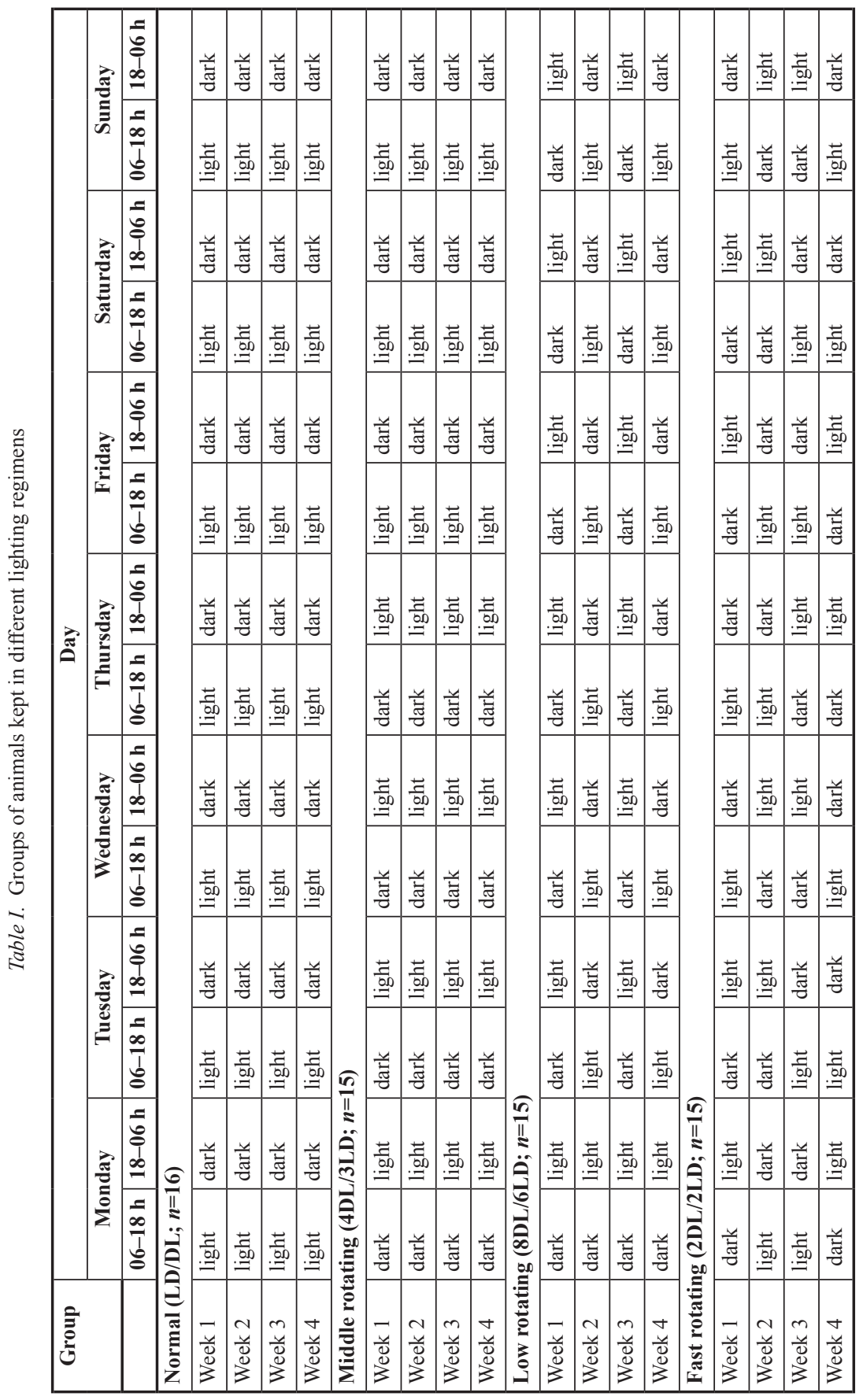


One subgroup from each group was created and, after a month-long adaptation period to the different lighting conditions, one group was subjected to chronic mild stress (CMS) while the other was left undisturbed with its daily routine (control group). Animals had free access to food and water, unless it was indicated otherwise by the experimental protocol. Altogether 61 rats were examined, that were handled in four separate groups according to the following principle: one group of 16 rats had four subgroups of four rats, and three groups of 15 rats had four subgroups: three subgroups with four rats and one subgroup with only three rats, all subgroups being kept in separate cages, also separated according gender. The current paper does not examine gender-related differences. The temperature was maintained at $23 \pm 2{ }^{\circ} \mathrm{C}$, with relative humidity of 60-70\%. Animal housing, care and the employment of experimental procedures were carried out in accordance with the EU directives and institutional guidelines under approved protocols.

\section{Chronic mild stress (CMS)}

After a month's adaptation period to the different lighting conditions, CSM protocol was employed, as suggested by Grippo et al. (15). The animals were exposed to the following different unexpected stressors daily for 4 weeks: water deprivation, continuous overnight illumination, cage tilt $\left(40^{\circ}\right)$, grouped housing, soiled cage, empty water bottle, strobe light, white noise and cold room ( $4^{\circ}$ Celsius). The control animals were left undisturbed during the 4-week period in their home cages, except for cage cleaning, feeding and weighing. The schedule for the CMS procedure is presented in Table II.

\section{Light-dark box test}

After the CMS procedure in the next LD period, a light-dark box test was used as one of the tests designed to examine anxiety-like behavior in case of the control groups and also the CMS-exposed groups. The device used for the test was a wooden box divided into two compartments (45 cm long, $24 \mathrm{~cm}$ wide and $23 \mathrm{~cm}$ high), with a $10 \times 8 \mathrm{~cm}$ narrow opening between them. The walls in one of the compartments were lit with white light from a halogen lamp (100 lux) while the walls of the other compartment were painted black and had no exposure to light. The rats were placed in the middle of the light compartment, and the activity was videotaped for five minutes. We measured the following parameters: time spent in the light, and number of transitions between the light and dark compartments $(5,24$, $37,39)$. Based on the protocol of the light-dark box test, anxiety-like behavior was proved in case of those animals, that spent significantly less time in the light compartment and changed compartments in the light-dark box significantly less often $(1,6,8,26,33,37)$.

\section{Data analysis}

Descriptive and inductive statistical analysis was carried out using SPSS for Windows 20 software. Differences between the subject groups were examined with one- and two-way analyses of variance (ANOVAs). Shapiro-Wilk test was applied to test normality, and Dunett's post hoc-test was used for group comparisons, at the significance level of $p<0.05$.

\section{Results}

Results of 61 animals were eligible for statistical data analysis according to time spent in light and the number of transitions. 

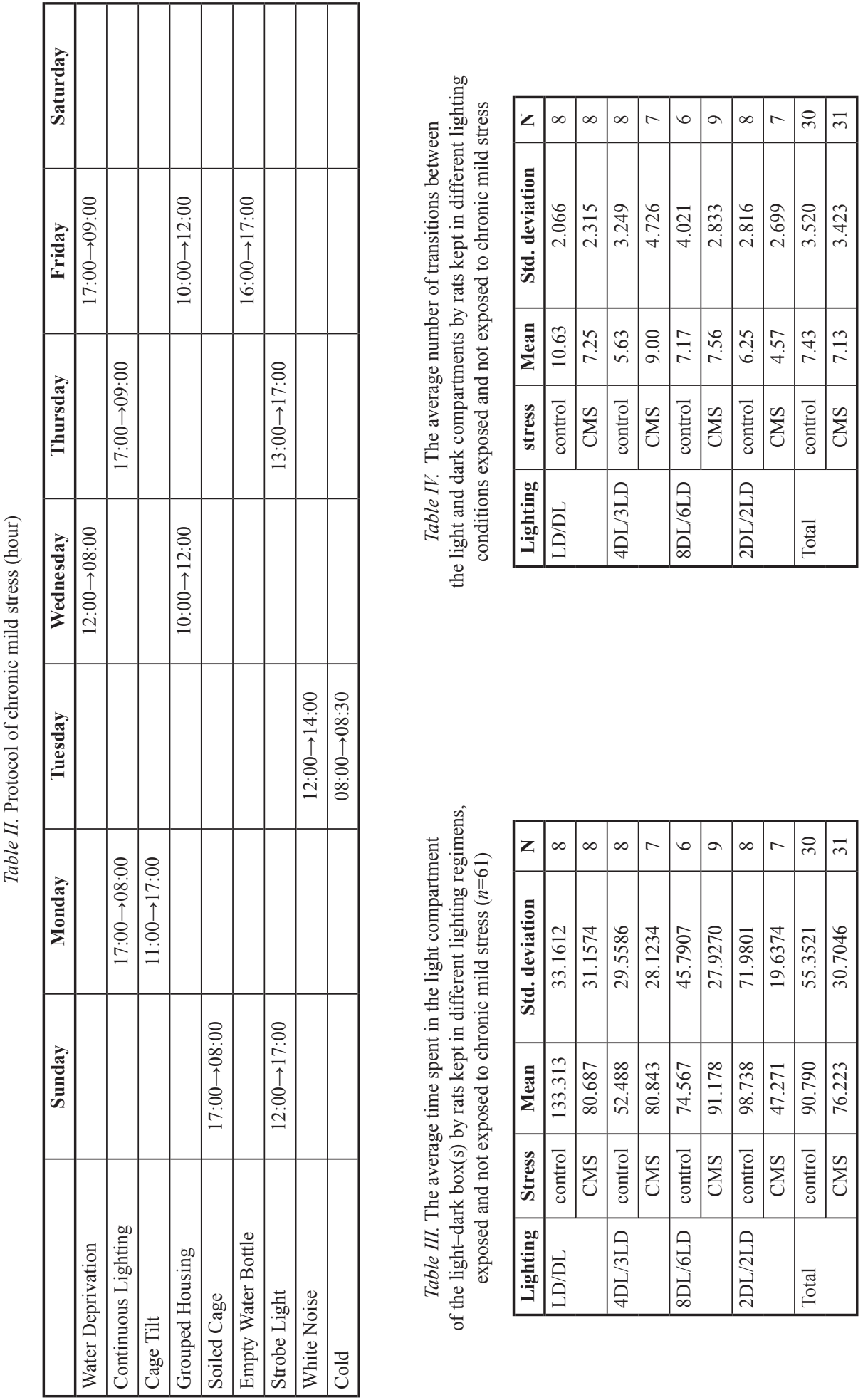
Time spent in the light compartment of the light-dark box

Animals $(n=61)$ spent $83.38 \pm 44.79$ seconds on average in the light compartment of the light-dark box. Average time spent in the light compartment is presented in Table III. Normality was examined and confirmed both with graphic and numeric methods. Both graphic tests (Q-Q plot, histogram) and the Shapiro-Wilk test confirmed normal distribution $(p>0.05)$. Average time spent in light concerning the different lighting regimens shows significant difference $(\mathrm{F}=2.67 ; p=0.05)$ (Fig. 1).

According to the Dunnet post hoc test applied for different lighting regimens, significant difference was found between the LD/DL and $4 \mathrm{DL} / 3 \mathrm{LD}$ groups $\left(p_{(\mathrm{LD} / \mathrm{DL} \text { vs. } 4 \mathrm{DL} / 3 \mathrm{LD})}=0.01 *\right.$; $\left.p_{\text {(LD/DL vs. } 8 \mathrm{DL} / 6 \mathrm{LD})}=0.27 ; p_{(\mathrm{LD} / \mathrm{DL} \text { vs. } 2 \mathrm{DL} / 2 \mathrm{LD})}=0.07\right)$.

Significant differences were found between lighting regimens according to the average time spent in light in case of control group $(\mathrm{F}=4.04 ; p=0.02)$ and chronic mild stress group $(\mathrm{F}=3.67 ; p=0.02)$.

The interaction of different lighting regimens and chronic mild stress significantly affects time spent in light $(\mathrm{F}=3.72 ; p=0.00)$. Examining the main effects, we may declare that interaction of lighting regimen and chronic mild stress is the most powerful factor concerning time spent in the light compartment of the light-dark box $(\mathrm{F}=4.65 ; p=0.00)$. Based on separate examination of the two main effects, we may state that lighting regimen is the most prominent factor $(\mathrm{F}=3.22 ; p=0.03)$ while chronic mild stress in itself did not have significant effect $(\mathrm{F}=2.16 ; p=0.148)$.

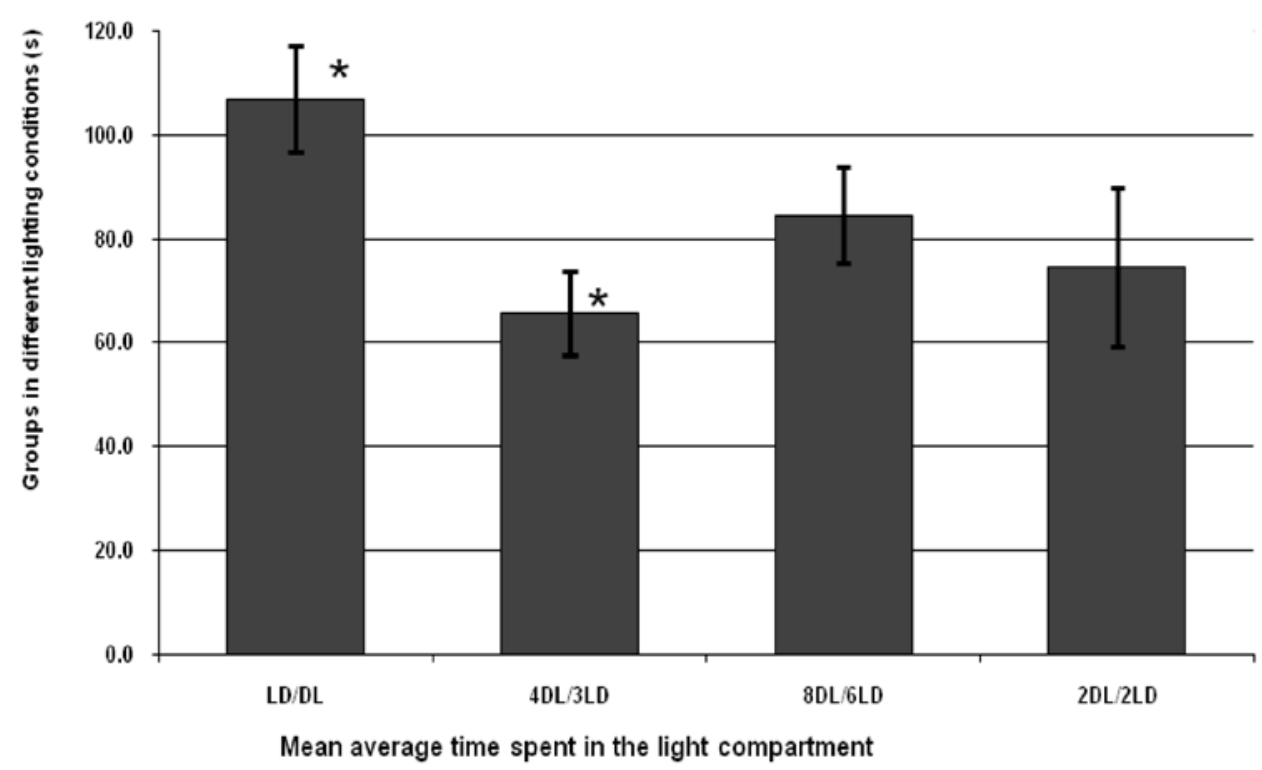

$p=0.05$ (ANOVA)

* One-way ANOVA Dunett post hoc

Fig. 1. Average time spent in the light compartment of the light-dark box by rats kept in lighting regimens according to different shift schedules $( \pm \mathrm{SE})(n=61)$ 


\section{Number of transitions}

The examined animals $(n=61)$ changed compartments in the light-dark box $7.28 \pm 3.45$ times on average (Table IV).

Regarding the number of average transitions one-way analysis of variance showed significant differences between the various lighting regimens $(\mathrm{F}=2.88 ; p=0.04)$ (Fig. 2). The Dunett post hoc test analysing various lighting conditions revealed significant difference between LD/DL and 2DL/2LD groups $\left(p_{(\mathrm{LD} / \mathrm{DL} \text { vs. } 4 \mathrm{DL} / 3 \mathrm{LD})}=0.33 ; p_{(\mathrm{LD} / \mathrm{DL} \text { vs. } 8 \mathrm{DL} / 6 \mathrm{LD})}=0.43 ; p_{(\mathrm{LD} / \mathrm{DL} \text { vs. }}\right.$ $\left.2 \mathrm{DL} / 2 \mathrm{LD})=0.01^{*}\right)$.

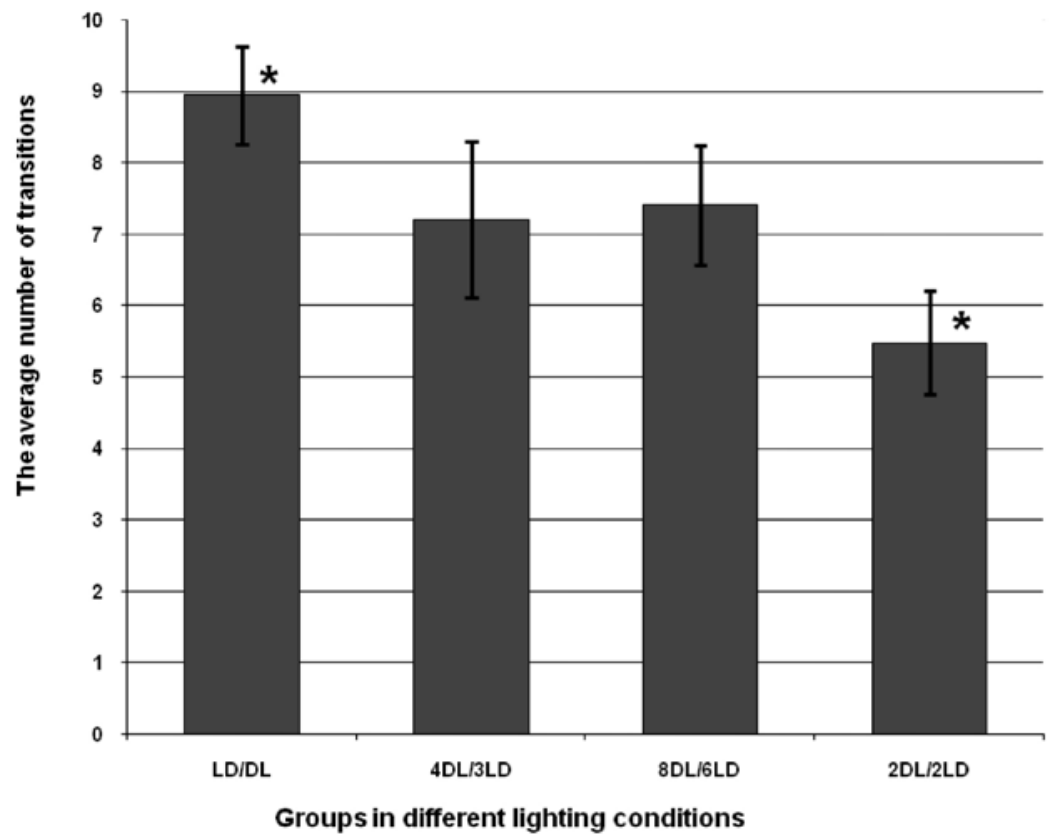

$p=0.04$ (ANOVA)

* One-way ANOVA Dunett post hoc

Fig. 2. Average number of transitions between the compartments of the light-dark box by rats kept in lighting regimens according to different shift schedules $( \pm \mathrm{SE})(n=61)$

While significant difference was observed $(\mathrm{F}=4.31 ; p=0.01)$ between lighting regimens in point of average transition numbers, there was only a small difference between lighting regimens in the group exposed to CMS $(\mathrm{F}=2.92 ; p=0.09)$.

The collective effect of lighting conditions and CMS on the number of transitions was examined with two-way variance analysis. We assessed that different lighting conditions and CMS together had a significant influence $(\mathrm{F}=2.81 ; p<0.01)$ on the average number of transitions by rats in the light-dark box which indicates the existence of interaction. Examining the main effects, it can be declared that the interaction of lighting conditions and CMS is the most prominent factor according to the number of transitions in the light-dark box $(\mathrm{F}=3.30 ; p<0.03)$. Lighting condition in itself is also significant $(\mathrm{F}=3.28 ; p<0.03)$, while CMS did not show significant influence $(\mathrm{F}=0.16 ; p>0.69)$. 


\section{Discussion}

Results regarding time spent in the light compartment of the light-dark box indicate that animals in the LD/DL control group spent the most time on average in the light compartment, and their behavior seemed to be the least anxious (Table III). In line with our expectations, average time spent in light decreased due to the application of CMS. Results show that time spent in the light compartment decreased significantly compared to the initial value (LD/DL control), both in case of the control group and in the CMS group. Based on the results it can be seen that CMS can be considered as a factor decreasing anxiety in case of middle (4DL/3LD) and low (8DL/6LD) rotating groups regarding lighting regimens, as animals exposed to CMS spend more time in the light compartment of the light-dark box than those with similar lighting conditions and not exposed to CMS, therefore CMS does not increase anxiety in these animals. Examining the interaction, we may claim that according to lighting conditions, time spent in the light compartment was not consistent in the control and CMS groups. It can be stated that lighting conditions are the most prominent influencing factors, since night shift schedule variations (control groups) alone lowered the average time spent in the light compartment in case of all lighting conditions.

We assessed that in point of interactions regarding lighting conditions the most endangered form is the fast rotating (2DL/2LD) schedule, as the appearance of CMS caused an intense increase of anxiety in rats. It means that the animals were unable to accommodate to the altered lighting conditions and to the repositioned normal lightings.

Results of the number of transitions in case of interaction show that animals in the LD/ DL control group spent the most time on average in the light compartment, namely their behavior seemed to be the least anxious. With the application of CMS the number of transitions decreased, which strengthened the applicability of the light-dark box method. Results show that compared to the initial value (LD/DL control) the number of transitions decreased significantly both in case of the control group and in the CMS-exposed group.

We also concluded that according to the number of transitions the most endangered form is the fast rotating (2DL/2LD) schedule, as the appearance of CMS caused an intense increase of anxiety in rats. It means that the animals were unable to accommodate to the altered lighting conditions and to the repositioned normal lightings. Our results prove that altered lighting conditions and CMS were tolerated better in the middle (4DL/3LD) and low (8DL/6LD) rotating groups.

This study has shown that lighting conditions seem to be the most prominent influencing factor from all others as the number of transitions in all lighting conditions in case of the control groups was lower than in the normal group (LD/DL) exposed to CMS (Table IV). Concerning time spent in the light compartment and the number of transitions in different lighting conditions, it can be stated that alterations appear in a similar tendency. Animals exposed to CMS in the normal (LD/DL) and fast rotating (2DL/2LD) group spent less time in the light compartment of the light-dark box, and the number of transitions between the two compartments were also fewer than in the control groups. Animals in the middle (4DL/3LD) and low (8DL/6LD) rotating group exposed to CMS spent more time in the light compartment and changed compartments more often. Lighting conditions alone influenced time spent in the light compartment as well as the number of transitions. However, animals being exposed to CMS under different lighting conditions had no influence in case of the middle (4DL/3LD) and low (8DL/6LD) rotating groups, suggesting that these groups were disturbed by the altered lighting conditions, while CMS did not have further influence on them qualifying as another stress factor. 
Our current results confirm our previous research mentioned in the literature overview, examining the effects of different lighting conditions and CMS on corticosterone and testosterone hormones. Based on the group averages in case of corticosterone the circadian rhythm showed a closely significant level in CMS-exposed groups with altered lighting conditions, while in groups which were not exposed to CMS the circadian rhythm of corticosterone cannot be observed. In case of testosterone, the circadian rhythm could be demonstrated in the CMS-exposed group, while in the group not exposed to CMS and kept between different lighting conditions the circadian effect of the hormone was ended (19, $30,32)$.

Results of the current study suggest the need for further human investigation enabling an optimal shift array, which may have the least negative effects on the health status of healthcare professionals. Based on this schedule, the body of healthcare professionals would be able to recover the most between different night shifts. This would decrease the risk of mistakes at work, which may facilitate the development of service quality, a more economic patient care and a positive change of patient satisfaction.

\section{REFERENCES}

1. Adamec R, Head D, Blundell J, Burton P, Berton O: Lasting anxiogenic effects of feline predator stress in mice: Sex differences in vulnerability to stress and predicting severity of anxiogenic response from the stress experience. Physiol. Behav. 88, 12-29 (2006)

2. Arimura M, Imai M, Okawa M, Fujimura T, Yamada N: Sleep, mental health status, and medical errors among hospital nurses in Japan. Ind. Health. 48, 811-817 (2010)

3. Bilkei-Gorzó A, Gyertyán I, Lévay G: mCPP-induced anxiety in the light-dark box in rats - a new method for screening anxiolytic activity. Psychopharmacology (Berl) 136, 291-298 (1998)

4. Borges FN, Fischer FM: Twelve-hour night shifts of healthcare workers: a risk to the patients? Chronobiol. Int. 20, 351-360 (2003)

5. Bouayed J, Rammal H, Younos C, Soulimani R: Positive correlation between peripheral blood granulocyte oxidative status and level of anxiety in mice. Eur. J. Pharmacol. 564, 146-149 (2007)

6. Bourin M, Hascoët M: The mouse light/dark box test. Eur. J. Pharmacol. 463, 55-65 (2003)

7. Caciari T, Tomei G, De Sio S, Capozzella A, Schifano MP, Trovè L, Casale T, Cardella C, Tomei F, Rosati MV: Evaluation of some cardiovascular risk parameters in health professionals exposed to night work. Ann. Ig. 25, 23-30 (2013)

8. Chotiwat C, Harris RB: Increased anxiety-like behavior during the post-stress period in mice exposed to repeated restraint stress. Horm. Behav. 50, 489-495 (2006)

9. Colorado RA, Shumake J, Conejo NM, Gonzales-Pardo H, Gonzales-Lima F: Effects of maternal separation, early handling, and standard facility rearing on orienting and impulsive behavior of adolescent rats. Behav. Processes 71, 51-58 (2006)

10. Davis S, Mirick DK, Stevens RG: Night shift work, light at night, and risk of breast cancer. J. Natl. Cancer Inst. 93, 1557-1562 (2001)

11. Fallis WM, McMillan DE, Edwards MP: Napping during night shift: practices, preferences, and perceptions of critical care and emergency department nurses. Crit. Care Nurs. 31, 1-11 (2011)

12. Farkas J, Reglodi D, Gaszner B, Szogyi D, Horvath G, Lubics A, Tamas A, Frank F, Besirevic D, Kiss P: Effects of maternal separation on the neurobehavioral development of newborn Wistar rats. Brain Res. Bull. 79, 208214 (2009)

13. Florida-James G, Wallymahmed A, Reilly T: Effects of nocturnal shiftwork on mood states of student nurses. Chronobiol Int. 13, 59-69 (1996)

14. Garbarino S: Shiftwork. Impact on health and safety in the working environment. G. Ital. Med. Lav. Ergon. 28, 89-105 (2006)

15. Grippo AJ, Beltz TG, Johnson AK: Behavioral and cardiovascular changes in the chronic mild stress model of depression. Physiol. Behav. 78, 703-710 (2003) 
16. Grønli, J, Murison R, Bjorvatn B, Sørensen E, Portas CM, Ursin R: Chronic mild stress affects sucrose intake and sleep in rats. Behav. Brain Res. 150, 139-147 (2004)

17. Hansen J, Stevens RG: Case-control study of shift-work and breast cancer risk in Danish nurses: Impact of shift systems. Eur. J. Cancer 48, 1722-1729 (2012)

18. Härmä MI, Ilmarinen JE: Towards the 24-hour society - new approaches for aging shift workers? Scand. J. Work Environ. Health 25, 610-615 (1999)

19. Józsa R, Halberg F, Cornelissen G, Zeman M, Kaszaki J, Csernus V, Katinas GS, Wendt HW, Schwartzkopff, Stebelova K, Dulkova K, Chibisov SM, Engebretson M, Pan W, Bubenik GA, Nagy Gy, Herold M, Hardeland R, Hütler G, Pöggeler B, Tarquini R, Perfetto F, Salti R, Oláh A, Csókás N, Delmore P, Otsuka K, Bakken EE, Allen J, Amory-Mazaudin C: Chronomics, neuroendocrine feedsidewards and the recording and consulting of nowcasts - forecasts of geomagnetics. Biomed. Pharmacother. 59, 24-30 (2005)

20. Karl T, Burne TH, Herzog H: Effect of Y1 receptor deficiency on motor activity, exploration, and anxiety. Behav. Brain Res. 167, 87-93 (2006)

21. Karlsson R-M, Holmes A, Heiling M, Crawley NJ: Anxiolytic-like actions of centrally-administered neuropeptide Y, but not galanin, in C57BL/6J mice. Pharmacol. Biochem. Behav. 80, 427-436 (2005)

22. Kim HI, Jung SA, Choi JY, Kim SE, Jung HK, Shim KN, Yoo K: Impact of shiftwork on irritable bowel syndrome and functional dyspepsia. J. Korean Med. Sci. 28, 431-437 (2013)

23. Knutsson: Shiftwork and myocardial infarction: a case-control study Occup. Environ. Med. 56, 46-50 (1999)

24. Luker FI, Mitchell D, Laburn HP: Fever and motor activity in rats following day and night injections of Staphylococcus aureus cell walls. Am. J. Physiol. Reg. I. 279, R610-616 (2000)

25. Marazzi A, Ruffieux C, Cornélissen G: Circadian and circaseptan patterns of natality and perinatal mortality of infants with different birth weights. Neuroendocrinol. Lett. 24, 105-110 (2003)

26. Matuszewich L, Karney .J, Carter SR, Janasik SP, O’Brien JL, Friedman RD: The delayed effects of chronic unpredictable stress on anxiety measures. Physiol. Behav. 90, 674-681 (2007)

27. Niu SF, Chu H, Chung MH, Lin CC, Chang YS, Chou KR: Sleep quality in nurses: a randomized clinical trial of day and night shift workers. Biol. Re.s Nurs. 15, 273-279 (2012)

28. Oláh A, Józsa R, Cornélissen G, Zeman M, Nagy Gy, Kaszaki J, Halberg F. Validation of exclusive daytime murine sampling on antiphasic lighting regimens by circadian rhytmic core temperature behavior. Proceedings of Symposium on Chronobiology in Medicine, Brno. pp. 100-101 (2004)

29. Olah A, Jozsa R, Cornélissen G, Csernus V, Zeman M, Nagy G, Halberg F: Sampling for chronomics extended circadian phase map of the laboratory rat. Proceedings, International Conference on the Frontiers of Biomedical Science: Chronobiology 46-49 (2006)

30. Oláh A, Jozsa R, Csernus V, Sandor J, Muller A, Zeman M. Hoogerwerf W, Cornélissen G, Halberg F: Stress, geomagnetic disturbance, infradian and circadian sampling for circulating corticosterone and models of human depression? Neurotox. Res. 13, 85-96 (2008)

31. Oláh A, Betlehem J, Müller A, Józsa R: Possible application of animal models for the long-term investigation of shift work of healthcare professionals. J. Perinat. Neonatal. Nurs. 22, 175-176 (2008)

32. Oláh A (2008): Long-term follow-up study in experimental animal model: exploration of circadian and extracircadian rhythms. The effects of altered exterior environment on the rhythms of the endocryne systems (In Hungarian: Biológiai ritmusok hosszútávú követése kísérletes állatmodellben: circadian és extracircadian ritmusok feltárása. Megváltozott külső környezet (fényviszonyok, elektromágnesesség, krónikus stressz) hatásai az endocrin rendszerek ritmusaira) $[\mathrm{PhD}$ dissertation] University of Pécs, Pécs

33. Pelloux Y, Costentin J, Duterte-Boucher D: Anxiety increases the place conditioning induced by cocaine in rats. Behav. Brain Res. 197, 311-316 (2008)

34. Simon F: Shift work, safety and aging. Chronobiol. Int. 25, 183-198 (2008)

35. Spurgeon A, Harrington JM, Cooper CL: Health and safety problems associated with long working hours: review of the current position. Occup. Environ. Med. 54, 367-375 (1997)

36. Straif K, Baan R, Grosse Y, Secretan B, El Ghissassi F, Bouvard V, Altieri A, Benbrahim-Tallaa L, Cogliano V: Carcinogenity of shift-work, painting, and fire-fighting. Lancet Oncol. 8, 1065-1066 (2007)

37. Suckow MA, Weisbroth SH, Franklin CL (2006): The laboratory rat. 2nd ed. Elsevier Academic Press, Boston

38. Takahashi M, Fukuda H, Miki K, Haratani T, Kurabayashi L, Hisanaga N, Arito H, Takahashi H, Egoshi M, Sakurai M: Shift work-related problems in 16-h night shift nurses (2): Effects on subjective symptoms, physical activity, heart rate, and sleep. Ind. Health 37, 228-236 (1999)

39. van Betteray JN, Vossen JM, Coenen AM: Behavioural characteristics of sleep in rats under different light/dark conditions. Physiol. Behav. 50,79-82 (1991)

40. Vogel M, Braungardt T, Meyer W, Schneider W: The effects of shift work on physical and mental health. J. Neural. Transm. 119, 1121-1132 (2012) 